\title{
EDUCAÇÃO SEXUAL, CRIANÇAS E MÍDIAS: ALGUMAS REFLEXÕES
}

\author{
Cristina VARELA ${ }^{1}$ \\ Sonia Maria Martins de MELO $^{2}$
}

RESUMO: O existir humano está diretamente ligado a percepção e vivencia de nossa sexualidade enquanto dimensão. E nesse sentido entender as relações sociais como relações de educação sexual são ponto fundamental para construirmos e vivenciarmos experiências e práticas humanas emancipatórias. Assim também devemos compreender as crianças, como seres sexuados em constante processo de educação sexual em suas relações com o Outro mediados pelo mundo, sendo este Outro crianças, adultos, seus brinquedos. Nessas relações estabelecidas pelas crianças, precisamos atualmente considerar as mídias como participantes dos processos de educação sexual vivenciados por cada um de nós seres humanos - crianças e adultos. Assim o presente artigo apresenta algumas reflexões que surgiram a luz do projeto de pesquisa em andamento que busca investigar as vertentes pedagógicas de educação sexual nos jogos online disponibilizados gratuitamente e produzidos especificamente para as crianças. $\mathrm{O}$ texto foi produzido a partir de um recorte teórico feito a luz de revisão de literatura sobre a educação sexual de crianças em sua interação com as mídias, refletindo-se mais especificamente sobre as possíveis influências nesse processo das vertentes pedagógicas existentes nos jogos online para a infância disponíveis hoje gratuitamente na internet, buscando subsidiar propostas emancipatórias sobre o tema.

PALAVRAS-CHAVE: Educação sexual. Vertentes pedagógicas de educação sexual. Jogos gratuitos online para crianças.

\section{Introdução}

A vivência humana plena de nosso corpo está diretamente ligada a compreensão e vivência de nossa existência como ser sexuado que somos. Assim há que se entender a vida e seus processos dialógicos também como expressão de nossa sexualidade no mundo, nas relações com o Outro. É portanto nesse desvelar de nossa dimensão sexualidade, dimensão ontológica, que podemos nos perceber como Seres sexuados no mundo. De acordo com Melo e Pocovi (2002, p.81):

Todos e todas são seres sexuados, e essa sexualidade se manifesta das mais diversas formas. Seja através dos sentimentos, das emoções, da

\footnotetext{
${ }^{1}$ Mestra em Educação. PPGE/UDESC - Programa de Pós -Graduação em Educação. Doutoranda. FURG - Universidade Federal do Rio Grande. PPGEC - Programa de Pós -Graduação em Educação em Ciências - Química da Vida e Saúde. Rio Grande - RS - Brasil. 96200-350 - cmonteggiavarela@ gmail.com.

2 Doutora em Educação. Professora. UDESC - Universidade do Estado de Santa Catarina. PPG em Educação. Florianópolis - SC - Brasil. 88035-001 - soniademelo@ gmail.com.
} 
relação sexual, do prazer. Essa "sexualidade" é parte indissociável de todos nós, em qualquer época de nossa vida, em qualquer ambiente, inclusive no escolar.

O existir humano no mundo é uma constante (re)construção, aí incluída a sexualidade, junto aos Outros seres, em diferentes contextos, diferentes tempos, em diferentes histórias, sendo a sexualidade então, por ser parte inseparável da pessoa, uma dimensão sócio-histórica e cultural construída no movimento dialético do Ser e Existir humanos. Como coloca Nunes (2005, p.15),

Pois falar sobre a sexualidade implica retomar alguns recursos metodológicos: a história, a antropologia, a moral e a evolução social. Não se fala da sexualidade de maneira fragmentada, dividida, estanque. As relações sexuais são relações sociais, construídas historicamente em determinadas estruturas, modelos e valores que dizem respeito a determinados interesses de épocas diferentes. Esse relativismo não pode ser irresponsável. Ele nos permite perceber a construção social da sexualidade sem contudo fazê-lo de modo destrutivo ou imaturo.

E reconhecermo-nos como seres sexuados é fundamental para entendermos nossas relações como processos de educação sexual. É no convívio diário - em nossas diversas relações sociais - que se constrói e se desenvolve nossas aprendizagens, sendo cada uma delas aprendizagem sempre sexuada, na busca dos Seres humanos pelo prazer, na vivência plena de uma amorosidade em suas várias formas. Nesse sentido Bernardi (1985) conceitua sexualidade numa perspectiva plena:

A sexualidade seria portanto uma qualidade típica e exclusiva do ser humano, porque só o homem é capaz de amor. A sexualidade não estaria necessariamente vinculada ao emprego de um órgão ou aparelho particular: o beijo, a carícia, o olhar, alguma percepção visual, ou olfativa, ou tátil, ou acústica, e até o puro pensamento, o sonho e o desejo, estariam todos na área da sexualidade enquanto veículos de prazer inseríveis na vivência de uma relação amorosa. $\mathrm{E}$ naturalmente a sexualidade seria totalmente independente da procriação, podendo exprimir-se de modos absolutamente estranhos à esfera genital. Em resumo, seria uma qualidade "global" do homem. (BERNARDI, 1985, p.114).

Assim, também devemos compreender a criança ${ }^{3}$, como ser sexuado que é, em busca de prazer, e vivência de amor. Desde recém-nascida a criança está em plena

\footnotetext{
${ }^{3}$ Adotamos como concepção de criança o conceito elaborado por Souza (2013, p.50), em sua dissertação: "a concepção de criança adotada neste projeto as vê e reconhece como sujeitos social e culturalmente ativos, que entendem e interagem com o mundo de acordo com as suas especificidades e contextos em que vivem as suas infâncias. Nesse sentido, numa perspectiva antropológica, tomamos cultura como a
} 
vivência de sua sexualidade, em relações sociais, também relações sexuais, construindose histórica e culturalmente, vivenciando sua vida-sexualidade, e manifestando-a nos diferentes espaços que a rodeiam.

De acordo com Nunes e Silva (2000) é preciso estimular pesquisas e estudos que fujam dos reducionismos históricos dos quais as crianças tem sido vítimas, reducionismos esses que lhe atribuem uma vivência assexuada, pura e angelical. A vivência da sexualidade infantil está presente e se manifesta em todas as suas relações, brincadeiras e experiências. É essa uma vivência “[...] que não tem vícios de disfarçar suas intenções e sensações, expressa com natural tranquilidade sua sexualidade junto com sua afetividade, sua criatividade, seu cansaço, enfim, tudo o que ela experimenta e vivencia". (NUNES; SILVA, 2000, p.76).

Nas palavras de Melo e Pocovi (2002, p.66) “[...] todas as crianças são sempre seres sexuados, desde o útero materno, sem exceção, e estão vivendo em suas famílias e no meio em que vivem, um processo permanente de educação sexual". Cabe a nós, adultos educadores, buscarmos a superação de uma visão negativa e repressora com a qual muitas vezes compreendemos as manifestações sexuais nessa faixa etária, na direção de uma compreensão das possibilidades de vivência dessa sexualidade como uma experiência sensível e rica em vida e afetos.

Bernardi (1985) nos ajuda a entender melhor essa visão negativa que se constrói sobre a sexualidade infantil. Para este autor tal fato está diretamente relacionado a necessidade dos adultos de se despojarem, negando ou reprimindo, sua própria sexualidade, uma vez que muitos a compreendem como algo sujo e negativo, devido a sua própria construção social, como sujeitos históricos que são. Nessa abordagem pretendem ver na criança um ser inocente, livre de toda essa "carga negativa" que envolve a sexualidade e assim, por esse viés expropriador dessa dimensão, des-sexualizam a criança, uma vez que,

[...] se a criança não fosse inocente o adulto não teria à sua disposição nenhuma referência para fundar a hipótese de uma não-sexualidade, não poderia sustentar a possibilidade concreta de uma existência separada do sexo e seria inexoravelmente condenado à repressão. (BERNARDI, 1985, p.47).

construção histórica de significados, valores, crenças, práticas e conceitos dos indivíduos que interagem em sociedade. Desta forma, entendemos que as crianças constituem suas culturas próprias de acordo com o contexto social em que vivem. 
A descorporificação do Ser humano inicia-se, portanto, juntamente com o início de sua vida, quando, desde suas primeiras manifestações no mundo, nega-se a vivência e existência de sua sexualidade. Para Melo (2004, p.39), “[...] nada é mais grave, nem mais triste, do que relações pedagógicas "descorporificadas", ou seja, que ignorem o corpo como ancoradouro do Ser no mundo, lugar de necessária vivência de todas as suas esperadas aprendizagens". É na segregação dessa dimensão que se constroem a maioria das relações sociais junto às crianças, visão essa calcada na repressão de suas expressões de amor e desejo.

A (re)descoberta da dimensão sexualidade é, antes de tudo, a aceitação plena da vida humana, inclusive entendendo-se o Ser como corporeidade, entendida como unidade de sua existência, na vivência da liberdade social, afetiva e emocional, num processo de emancipação concreta das pessoas, ai incluídas nossas crianças, seres também de desejos.

Como coloca Andrade (1995, p.11):

\begin{abstract}
A construção da sexualidade abrange o que significa "ser menino" ou "ser menina", homem ou mulher, numa dada cultura; a manifestação dos sentimentos, a maneira de ver o mundo, que acabam por refletir as estruturas cognitivas e afetivas, construídas ao longo do processo de desenvolvimento. Nessa construção inclui-se a categoria do desejo, que é a moda da reconstrução, numa dinâmica micro, do conhecimento socialmente compartilhado. O desejo imprime um estilo pessoal e um ritmo ao movimento da construção do corpo sexuado, cognitiva e afetivamente.
\end{abstract}

E essa construção é base da educação e da vivência de cada criança em seu meio, é expressão de suas relações com o Outro, sendo este criança, menino, menina, adulto, pai, mãe. Também está presente nas suas relações com outros espaços e meios sociais, outras formas de linguagem, que constantemente permeiam suas relações, tais como aquelas expressas pela televisão, pelo rádio, pelos filmes e desenhos animados, pelos videogames e demais materiais utilizados via computadores, etc. São hoje muito diversas as várias linguagens midiáticas que permeiam o cotidiano contemporâneo. Todas elas também produzem e reproduzem, com seus conteúdos para as crianças, ou com elas, relações e vivências humanas, todas elas sexuadas.

Portanto, tratar com sensibilidade a temática da dimensão da sexualidade infantil, antes de mais nada, não é segregá-la de seu contexto ou destituí-la de sua expressão, mas sim contextualizá-la na vida, na estrutura social e cultural em que está presente, reconhecendo sua relação permanente com a vida humana, pois dela é 
inseparável, e aqui, em nossas reflexões, refleti-la no seu entrelaçamento com a vivência das crianças, vivência essa hoje permeada de contatos com várias ferramentas midiáticas. Nessa perspectiva,

O contexto cultural do qual a criança participa e as práticas sociais historicamente constituídas são incorporadas por ela, ativamente, essa rica experiência acumulada pela humanidade, possibilita a criança aprender pela palavra do outro, organizando os próprios processos mentais e as suas ações. É por esse processo que se constrói o senso de si mesmo, como indivíduo único que está em constante transformação. (ANDRADE, 1995, p.27).

Refletir sobre a vivência da sexualidade infantil no seu contexto de relações passa por observar diferentes exemplos do cotidiano, pois a criança interage e aprende não somente com seus pais e familiares próximos, mas também na escola com seus colegas e professores, na rua com outros tipos de relações que se estabelecem também por meio da mídia que a cerca. Nesse interim o "não" diálogo intencional sobre a sexualidade com essa criança, sem que ocorra uma intervenção sensível de um adulto dialogando com ela sobre o que lhe está sendo comunicado por essas mídias, deixa-a completamente sozinha para testar, conhecer e aprender ou desaprender sobre sua sexualidade, frente a esses estímulos plenos de mensagens. Adultos que se omitem dessa relação pedagógica de dialogar com sensibilidade e sobre as várias faces dessa temática da sexualidade que inclusive são expostas por várias mídias são os mesmos que, sem saber, são todos educadores sexuais em suas relações sociais, num poderoso currículo oculto, mesmo sem ter noção de que esse currículo é sempre resultado de um diálogo, mesmo que silencioso.

Como coloca Freire (1988, p.69), “[...] educação é comunicação, é diálogo, na medida em que não é a transferência de saber, mas um encontro de sujeitos interlocutores que buscam a significação dos significados”. Partindo do pressuposto de que todos os seres humanos educam-se uns aos outros pelas relações sociais que estabelecem entre si, relações essas sempre sexuadas, e considerando a sexualidade como dimensão ontológica, nós podemos afirmar que os seres humanos estão em permanente processo de educação sexual em suas vivências diárias, hoje com essa vivência perpassada intensamente pelas mensagens midiáticas. Melo e Pocovi (2002) discorrem a respeito do assunto, pois para ambas a educação:

[...] é um fenômeno humano e social, com todas as suas determinações, sendo também campo de ação humana. Relembre que 
toda a sociedade ou qualquer grupo social são sempre agências educadoras num permanente processo educacional. Isso porque educação não se reduz à escolarização ou à instrução já que se entende que educar é construir redes de significações culturais e comportamentos padronizados, de acordo com os códigos sociais vigentes. A educação sexual, com todos seus componentes explícitos, formais e não formais, não escapa a essa dimensão sociopolítica e cultural. (MELO; POCOVI, 2002, p.29).

A educação sexual sempre permeia todos os espaços e relações sociais.

Portanto esse processo de educação sexual existe como parte inseparável da educação das crianças, desde sempre, e perpassa a infância em todos seus momentos, nas conversas e diálogos com amigos ou outros adultos, na execução de suas tarefas, nas brincadeiras, no uso do computador e outras ferramentas tecnológicas, ao assistirem filmes e desenhos e ao utilizarem jogos online, por exemplo. Esse fato concreto diversas vezes passa despercebido por professores e professoras da educação infantil, principalmente pela dificuldade de reconhecerem as crianças com sua sexualidade. Além disso, a maioria entende que, a educação sexual acontece apenas em momentos preparados e escolhidos intencionalmente, sendo que, por esse motivo, esquecem-se de olhar para a tecnologia e para as mídias como produtos de seres humanos, plenos de intenções, participantes/influenciadoras dos processos de educação, sempre também de educação sexual das crianças.

É preciso buscar exercitar sempre um olhar crítico sobre esse processo, ao construirmos propostas de educação sexual que sejam intencionais, numa perspectiva emancipatória, para nossos espaços educativos formais e não formais, concordando com Figueiró (2006, p.3) quando a mesma define:

[...] educação Sexual como sendo toda ação ensino-aprendizagem sobre sexualidade humana, seja no nível do conhecimento de informações básicas, seja no nível do conhecimento e/ou discussões e reflexões sobre valores, normas, sentimentos, emoções e atitudes relacionados à vida sexual.

Pensar propostas de educação sexual nessa abordagem é fundamental para se pensar na transformação do futuro. A vivência saudável das pessoas requer de nós, seres sociais, uma decisão consciente e crítica em nossas escolhas pedagógicas. Diante dessa imensa tarefa, cabe também aos educadores o estudo e debate intencional sobre a temática educação sexual nas instituições de ensino onde atuam, buscando desvelar criticamente o processo existente de educação sexual mediante os processos pedagógicos presentes nas relações lá estabelecidas no cotidiano. Em contrapartida, se 
vivenciamos no cotidiano essas experiências como não-diálogos, pela dificuldade e insegurança de se falar no tema, a negação do tema na escola pelos educadores pode estar refletindo um entendimento, por parte dos educadores de que, por não tocarem no assunto, "não fazem educação sexual", sem ter noção de que, com suas práticas pedagógicas, educam sim sexualmente, a cada minuto de cada dia.

Para Bernardi (1985) a educação sexual que permeia as práticas educativas na sociedade ocidental contemporânea "[...] é orientada para a repressão, é na verdade dessexualizante e genitalizante." (BERNARDI, 1985, p.107). E nessa perspectiva “[...] a criança acaba se convencendo rapidamente de que o sexo é alguma coisa proibida, vergonhosa e nefasta”. (BERNARDI, 1985, p.26).

Há que se repensar a educação sexual que tem permeado a educação das nossas crianças. Reafirmamos que a construção de propostas que proporcionem o reconhecimento e retomada da compreensão plena da corporeidade dos seres humanos numa perspectiva emancipatória, de cidadania plena, é somente possível quando se possibilita o reconhecimento da sexualidade como dimensão humana, como expressão e vivência dos seres no mundo, em suas relações com os Outros.

Encontramos em Silva (2001) palavras que nos ajudam a ressignificar a educação sexual, quando a autora coloca o que seria a vivência de uma abordagem de educação sexual emancipatória como:

[...] o resgate da compreensão ampla do corpo, que redundaria numa nova estética, do seu sentido filosófico de respeito e compreensão dialética da corporeidade, não clivada de si, a reflexão crítica dos papéis sexuais e dos modelos estereotipados de homem e mulher, a superação do egocentrismo que desbloqueia a afetividade e possibilita a partilha significativa das vivências sexuais, a aproximação do universo sexual como parte dialética da vida intelectual, do trabalho e das estruturas sócio-políticas, a compreensão pedagógica dos diferentes níveis do desenvolvimento humano integrando as dimensões do campo "lógico-cognitivo e sócio afetivo". (SILVA, 2001, p.264).

Hoje uma expressão emancipatória da Educação Sexual é a que se expressa na Declaração dos Direitos Sexuais como Direitos Humanos Universais ${ }^{4}$, pela qual podemos aprofundar, de forma enriquecedora, a compreensão sobre toda a necessidade política, social e cultural que engloba a vivência e desenvolvimento da sexualidade humana.

\footnotetext{
${ }^{4}$ Promulgada no XV Congresso Mundial de Sexologia (WAS), realizado na China em 1999. Texto integral em Melo e Pocovi (2002, p.44).
} 
Aponta o décimo item da declaração sobre o Direito à educação sexual compreensiva, como sendo este "[...] um processo que dura a vida toda, desde o nascimento pela vida afora, e que o mesmo deve envolver todas as instituições sociais.” (MELO; POCOVI, 2002, p.45). Assim, pensar a educação sexual das crianças, seres sempre sexuados no mundo junto a outros seres, é buscar sensibilizar educadores e educadoras sobre a pertinência da abordagem de tal tema em ser aprofundado em pesquisas e estudos no campo educacional hoje, principalmente nesse mundo permeado de novas mídias.

$\mathrm{Na}$ sociedade atual a mídia é parte integrante de nosso dia-a-dia. A criança nasce já inserida neste mundo midiático, onde a informação é facilmente acessada. Diariamente diferentes imagens e conceitos lhe são apresentados, discutidos e abordados por diversas mídias, em vários tipos de produções humanas. Neste contexto a criança se constrói e reconstrói, desenvolvendo seus valores, reinterpretando, com apoio de um educador ou sem ele, as informações que pelas mídias lhe são passadas. Perceber a presença dos computadores e da internet, e seus derivados, como parte direta ou indireta da rotina diária da criança, é fundamental para afirmar a necessidade de se desenvolver um olhar crítico sobre os conteúdos que os mesmos oferecem e que fazem parte da rotina infantil.

Assim, à medida que a criança cresce e deixa de ser um bebê educado pela família e depois pela escola, passa a ter maior contato com o resto do mundo. Sua educação, queiram seus responsáveis ou não, extrapola os valores transmitidos pelo seio familiar e pelo ambiente escolar. As crianças, quando confrontadas nos demais espaços sociais por diferentes valores, alguns muito fortemente divulgados pelas mídias, assimilam, na maioria das vezes sem reflexão, esses conteúdos e passam a vivenciá-los e transmiti-los em seu universo cotidiano.

Nesse entendimento, oportunizar um espaço de uso, discussão e interação dos professores e professoras com os conteúdos presentes nos jogos online para crianças hoje existentes e disponíveis em várias mídias, é ponto fundamental do projeto de pesquisa em andamento, tendo em vista as expressivas relações mediadoras entre as pessoas propiciadas por esse espaço, por meio do acesso as suas informações pelas crianças. Em nossa sociedade hoje é fácil perceber que o sexo e a sexualidade são alguns dos principais ingredientes usados em vários conteúdos dessa mídia para estimular o consumo, inclusive junto às crianças. Nunes (2005), por exemplo, é um dos 
autores que nos proporciona uma visão de como está sendo vinculada atualmente nas mídias a imagem de homens, mulheres e crianças:

[...] os meios de comunicação e a propaganda, na medida em que ampliaram sua influência social e sua função ideológica, assumiram a sexualidade e suas representações de desejo e anseio, contidas nas lutas dos jovens, para uma outra dimensão, o consumo e a alienação objetual. Hoje tudo se encontra sacramentado com o apelo do sexo. $\mathrm{O}$ corpo da mulher, e cada vez mais o do homem, é o lugar-tenente do enquadramento estético, moral e econômico. Os astros e estrelas são os grandes veículos das novas estruturas de ser homem ou mulher. (NUNES, 2005, p.21).

Diferentemente de nós, adultos, a criança, muito mais suscetível às informações que lhe transmitem, acaba por construir e inculcar acriticamente, facilmente, em seus valores e ideias, diferentes conceitos e leituras de mundo que brotam dessas mensagens midiáticas hoje, nem todos humanizadores. Aponta Felipe (2003, p.120) que a “[...] medida em que as crianças têm sido alvo de um forte apelo comercial, sendo descobertas como consumidoras e, ao mesmo tempo, como objetos a serem consumidos", colocamo-las em uma situação de vulnerabilidade por abrirmos espaço para diferentes formas acríticas de leitura e interpretação dos ideais de consumo de nossa sociedade.

Da mesma forma que estimulamos, mesmo sem termos consciência disso, as crianças a consumirem e utilizamos a representação de sua imagem nos mais diferentes programas, desenhos e sites infantis, construímos ainda, por meio dessas linguagens midiáticas, uma imagem de criança também para o "nosso consumo". Abrimos assim espaço para uma nova forma de exploração da criança e, assim da infância, mesmo que em vários documentos e normas existentes, registremos que buscamos respeitá-la e dela cuidar:

As representações sobre sexualidade, corpo e gênero, veiculadas em especial pela mídia, têm subjetivado não só adultos, homens e mulheres, mas também têm trabalhado minuciosamente para a formação das identidades infantis e juvenis nos nossos dias. Os corpos vêm sendo instigados a uma crescente erotização, amplamente veiculada através da TV, do cinema, da música, em jornais, revistas, propagandas, outdoors, e, mais recentemente, com o uso da internet, tem sido possível vivenciar novas modalidades de exploração dos corpos e da sexualidade. Tal processo de erotização tem produzido efeitos significativos na construção das identidades de gênero e identidade sexuais das crianças. (FELIPE, 2003, p.128). 
Nunes (2005) também nos alerta sobre o desenvolvimento das crianças e dos jovens hoje ser bombardeado por esse mundo de informações, produzida por pessoas para pessoas, sempre com intencionalidade, que abrem espaço para todo o tipo de conceito e ideia com um único objetivo: a venda. Neste meio a sexualidade na sociedade contemporânea assume papel central. A venda da sexualidade, seu erotismo, suas formas e possibilidades se tornam hoje "a melhor campanha publicitária". E portanto "[...] a expansão da sexualidade quantitativa, mecânica, genital, consumista e generalizada baniu as relações de significação e sentido. Até o amor e as relações entre os sexos assumiram esse caráter”. (NUNES, 2005, p.132).

Agora consumimos corpos, alimentamo-nos de um "prazer mercadológico" e acabamos por viver em busca dele. A compulsão por esse tipo de prazer constrói em nós não apenas um sentimento de superficialidade, bem como de desrespeito para com o nosso corpo e nosso ser. Portanto a criança nesse contexto é também educada pelas propagandas e programas presentes na mídia, especialmente aqueles feitos para seu consumo.

Highwater (1992, p.170) também discorre sobre esse consumo dos corpos:

[...] a transformação do corpo humano em mercadoria não é senão um dos resultados da comercialização do sexo. O ideal da liberdade de expressão, que abriu as portas à reprodução do ato explicito, tem o seu lado sombrio: molestamento de crianças, estupros, mutilações sexuais e violência.

Com essa perspectiva como base de nossas reflexões é fundamental desenvolvermos propostas de educação sexual emancipatórias para vivenciá-las desde os primeiros anos de vida das crianças e ao longo de todo o seu crescimento e desenvolvimento. Apenas com a retomada de nossa sexualidade como dimensão política, romântica, prazerosa, cheia de vida e força, como expressão humana plena, é que poderemos repensar as relações humanas e desmistificar diferentes tabus que permeiam a sociedade ocidental contemporânea. E nesse sentido é importante retomarmos mais algumas reflexões e alertas de Bernardi (1985) sobre o tipo de educação sexual que tem permeado as relações humanas. Para esse autor,

[...] a educação sexual contribui de três modos para a coisificação do sexo: primeiro, como vimos, com uma resignação suspeita; segundo justificando-lhe a existência, especialmente a nível de prostituição; terceiro, mascarando-lhe a verdadeira face até sua institucionalização. Isto é, fazendo passar por coisa normal, incensurável e até louvável o que na verdade é desumanizante e humilhante, cobrindo com o manto 
da legalidade um mercado em si degradante, colocando a etiqueta do matrimônio sobre uma contratação muito distante da esfera afetiva e muito próxima da esfera econômica. (BERNARDI, 1985, p.111).

Há que desvelar criticamente, contrapondo propostas emancipatórias, essa perspectiva de se manter uma educação sexual alienante e desumanizadora, onde passase a coibir e denegrir qualquer demonstração e manifestação humanizadora da sexualidade humana. Reafirmamos que nessa perspectiva a criança é tida como ser puro e angelical e é envolvida num manto assexuado. Há que se denunciar que, na perspectiva de se permanecer nessa abordagem, isto tem permitido, inclusive, que se coloque hoje na sexualidade um rótulo mercadológico de "liberdade", onde até se dá a ela um espaço, mas controlado, onde sua aceitação, de forma parcial no meio social, é unicamente possível por sua compensação financeira, fruto da venda dessa preciosa mercadoria. E essa venda acontece muitas vezes subliminarmente para nossas crianças, com o que lhes é proposto em vários dos conteúdos de jogos online a elas destinados.

De acordo com Santaella (2013, p.219),

\begin{abstract}
A importância crescente que a "cultura gamer" vem desempenhando na sociedade, com inegável impacto no conceito de entretenimento, educação e treinamento, só é ignorada por poucos, e o game como produto cultural é visto, sob diversas perspectivas, enquanto mídia, manifestação de arte, nova forma de aprendizagem e até como o mais recente ícone da cultura pop, o que só vem comprovar cada vez mais a notável influência e relevância cultural dos games na contemporaneidade. Poucos têm ainda dúvidas de que se trata de um expressivo e complexo fenômeno cultural, estético e de linguagem que foi capaz de desenvolver, em seu curto período de existência, toda uma retórica própria que não cabe negligenciar.
\end{abstract}

Tal processo, contudo, ainda pouco tem sido abordado por estudos sobre sexualidade e educação sexual de crianças, campo esse fundamental para nossas reflexões, principalmente quando compreendemos ser a sexualidade uma dimensão ontológica e a educação sexual parte constante de nossas relações sociais. Assim, olhar criticamente para o que as crianças estão aprendendo sobre sexualidade e educação sexual via uso dos jogos online, é fundamental para que busquemos a construção de projetos de educação sexual intencionais, com propostas emancipatórias, procurando problematizar as dinâmicas, objetivos e propostas presentes nessas atividades de entretenimentos disponíveis, muitas vezes gratuitamente, nos vários sites dirigidos para crianças. 
De acordo com Moraes e Schmidt (2010), é importante desvelarmos o espaço da mídia como um espaço pedagógico que também exerce influência na educação das crianças, contribuindo em seus processos de educação sexual, gênero e identidade. Nesse sentido, as autoras ainda discorrem sobre os tipos de brinquedos destinados a meninos e meninas, sendo os:

[...] brinquedos que envolvem aventura como característica principal, dirigida ao público infantil, são oferecidos aos meninos e, os que minimizam as funções das mulheres à maternidade, à preocupação com beleza e consumo, são direcionados às meninas. (MORAES; SCHMIDT, 2010, p.3).

Da mesma forma, as autoras continuam a evidenciar que, assim como os brinquedos, os conteúdos reproduzidos pela mídia às crianças, compartilham dessa mesma perspectiva, evidenciando símbolos ditos para meninos como força, coragem, virilidade, e que em contra partida, neles também aparece a preocupação de apresentar para as meninas o reforço de um padrão de mulher dócil, fazendo a contraposição fortefraco, delicado-viril (MORAES; SCHMIDT, 2010). Ainda nas palavras dos autores,

[...] podemos entender que a sociedade, de uma maneira geral - que reflete na construção da cultura infantil -, investe em comportamentos padrões, fazendo com que os sujeitos se portem "dessa" ou "daquela" maneira, e isso vai se constituindo através dos brinquedos, jogos e brincadeiras, por exemplo, que proporcionamos às crianças. (MORAES; SCHMIDT, 2010, p.7).

Portanto, entendemos ser fundamental hoje, com o intuito de se repensar nesse novo espaço de interação para as crianças que vem se constituindo na mídia, o desvelamento as vertentes pedagógicas de educação sexual existentes nos jogos online disponíveis gratuitamente para crianças, nos mais variados sites. São jogos de habilidades, estratégias, quebra-cabeças, sobre bonecas, etc., que tem muitas vezes como um dos principais personagens aqueles de desenhos e filmes infantis de sucesso. Em nossas análises temos percebido que muitos desses jogos vem classificados em duas grandes categorias: "jogos de meninos" e "jogos de meninas", e são facilmente encontrados na rede, através das palavras de busca “jogos de/para crianças” pelo navegador GOOGLE. Nessa seleção que fizemos a priori dessa classificação feita nos sites, e com uma análise prévia do conteúdo respectivo de cada jogo, já percebemos fortes indicadores de existir ali o reforço da padronização e naturalização de papéis estereotipados do que seria ser homem e ser mulher nos dias de hoje. 
Refletindo sobre a "cultura gamer" Santaella (2013) já aponta para o fato de que,

[...] não se pode ignorar que os games muitas vezes incorporam temas antissociais que incentivam o antagonismo e incluem roubo, violência e ferimentos, crueldade e representações problemáticas do corpo em termos de gênero e raça. Até mesmo situações competitivas maldosas são encorajadas quando ganhar é o alvo exclusivo do jogo. (SANTAELLA, 2013, p.222).

Nossa preocupação, hoje porém, vai além do que muitas vezes até percebemos claramente, como os aspectos apontados por Santaella (2013). Entendemos ser urgente desenvolver proposta de se pesquisar as vertentes pedagógicas de educação sexual de crianças que estão envolvidas nos conteúdos expressos por esses jogos online, como apoio à processos de formação regular e continuada de educadores, em projetos intencionais de formação que busquem desenvolver um olhar crítico dos profissionais da educação sobre os conteúdos desses jogos, reconhecendo, assim, as vertentes de educação sexual que os permeiam, refletindo sobre elas. Essa reflexão pode auxiliá-los na ressignificação de suas práticas pedagógicas.

Nessa direção relembramos a importância dos estudos desenvolvidos por Felipe e Prates (2012) que discorrem sobre a erotização dos corpos infantis, a pedofilia e a pedofilização da infância na contemporaneidade, presentes nos sites infantis. De acordo com as autoras, "[...] as crianças, em especial as meninas, têm sido colocadas como possibilidade de experimentação do desejo sexual adulto, bem como têm sido estimuladas a produzirem seus corpos, de acordo com os ditames culturais de embelezamento". (FELIPE; PRATES, 2012, p.1).

Nesses estudos desenvolvidos por Felipe e Prates, alguns dos sites analisados, apresentaram conteúdos estimulando crianças a se beijarem escondidas, fazendo diferenciação dos papeis de gênero, ressaltando a identidade heterossexual, enfim contribuindo para a disseminação de estereótipos e padrões socialmente e culturalmente aceitos como únicos e verdadeiros.

Outro ponto ressaltado pelas autoras é no que concerne as armadilhas que a rede apresenta:

Geralmente os sites classificados como "infantis" possuem portas de acesso para páginas eróticas ou com materiais pornográficos e também a diversas salas de bate-papo. A divulgação de materiais de cunho erótico é feita através dos próprios sites por meio de ícones (em 
geral desenhos ou palavras estrangeiras), muitos dos quais sem aviso ou qualquer restrição. (FELIPE; PRATES, 2012, p.12).

Mas entendemos também que é necessário, além de se evidenciar as armadilhas que permeiam os sites infantis e seus conteúdos, aprofundar com nosso estudo específico em andamento, o desvendamento das vertentes pedagógicas de educação sexual existentes nos conteúdos específicos de jogos online disponíveis gratuitamente na internet para crianças de diferentes idades. Jogos que necessitam apenas de uma criança para usá-los, mesmo que ainda não seja uma leitora alfabetizada, e que estão sendo cada vez mais pensados para o público de 0 a 6 anos, que nascem inseridos nessa sociedade midiática, onde o computador, antes de ser visto como uma ferramenta de trabalho e estudos, já é percebido por elas como um brinquedo, uma porta de acesso para um mundo mágico, encantado.

Pautamo-nos na nossa caminhada investigativa, como ponto de partida para a análise dos conteúdos dos jogos online para crianças, nos estudos de Nunes (1996), que apresenta quatro vertentes pedagógicas brasileiras de educação sexual, por ele cunhadas de repressoras e denominadas de vertente médico biologista da sexualidade, vertente normativa-institucional, vertente consumista e quantitativa pós-moderna e a vertente terapêutico-descompressiva, além de apontar uma quinta vertente, denominada de emancipatória.

Durante a fase inicial do projeto, a revisão da literatura do tema demonstrou ser esse um campo pouco explorado, principalmente no que concerne ao estudo de conteúdo de educação sexual existentes nos jogos online, bem como é mínima a legislação reguladora de mídia para criança no Brasil, pois encontramos apenas alguns apontamentos e análises dos marcos regulatórios de outros países.

Entendemos que refletir cada vez mais sobre esse tema tem se mostrado fundamental, como foi apontado por Felipe e Prates (2012), demonstrando serem esses sites infantis espaços de livre acesso, sem controle nenhum sobre seus conteúdos, tendo nesses espaços um entretenimento gratuito, ricos de cores, criatividade, interação e animação, mas também repletos de jogos e brincadeiras que ainda reforçam a identidade heterossexual como padrão, com os papeis de gênero masculino e feminino apresentados em sua maioria, como representações de estereótipos de homens fortes e viris e mulheres dóceis e maternais, como discorrem Morais e Schmidt (2010).

Reafirmamos que é preciso pensar na intencionalidade e na visão de mundo que permeiam essas novas linguagens midiáticas, pois temos que lembrar ser a mídia 
produto humano, feito por humanos, para humanos, carregado de intencionalidade. Intencionalidade essa que está plena, mesmo que muitas vezes oculta ou negada, nos processos de educação das crianças, e assim, de sua educação sexual, tudo isto ocorrendo hoje com muita força inclusive em jogos online aparentemente "inocentes e assexuados".

\section{SEXUAL EDUCATION, CHILDREN AND MEDIA: SOME ISSUES NECESSARY}

ABSTRACT: The human existence is directly linked to perception and experiences of our sexuality as a dimension. In that sense, understand social relations as relations of sex education are fundamental point to build and live experiences and human practices emancipatory. We must also understand children as sexual beings in a constant process of sex education in their relations with the Other mediated by the world, and this Other children, adults, their toys. The relationships established by the children, we need now to consider the media as participants in the processes of sexual education experienced by each of us human beings - children and adults. Thus this paper presents some reflections that emerged light of ongoing research project that seeks to investigate the pedagogical aspects of sex education in online games freely available and produced specifically for children. The text was produced from a theoretical framework made light of literature review on sexual education of children in their interaction with the media, reflecting more specifically on the possible influences in this process of existing pedagogical approaches in online games for childhood now available for free on the Internet, seeking support emancipatory proposals on the subject.

KEYWORDS: Sex education. Pedagogical approaches of sex education. Free online games for kids.

\section{REFERÊNCIAS}

ANDRADE, C. M. R. O dito, o explícito e o oculto na fala das crianças sobre sexualidade humana. Campinas: Ed. da UNICAMP, 1995.

BERNARDI, M. A deseducação sexual. 2.ed. São Paulo: Summus, 1985.

FELIPE, J. Erotização dos corpos infantis na sociedade de consumo. Revista Pro-

Posições, Campinas, v.14, n.3, p.119-130, set./dez. 2003. Disponível em

<http://www.proposicoes.fe.unicamp.br/ proposicoes/textos/42-dossie-felipej_etal.pdf> Acesso em: 25 ago. 2011.

FELIPE, J; PRATES, L. M. Erotização dos corpos infantis, pedofilia e pedofilização na contemporaneidade. In: IX ANPED SUL SEMINÁRIO DE PESQUISA EM EDUCAÇÃO DA REGIÃO SUL, 2012, Caxias do Sul. Anais... Caxias do Sul: ANPED, 2012. Disponível em: 
<http://www.portalanpedsul.com.br/admin/uploads/2012/Genero,_Sexualidade_e_Educ acao/Trabalho/12_42_52_2538-7464-1-PB.pdf.>. Acesso em: 20 nov. 2012.

FIGUEIRÓ, M. N. D. Formação de educadores sexuais: adiar não é mais possível. Campinas: Mercado das Letras; Londrina: Ed. Eduel, 2006.

FREIRE, P. Extensão ou comunicação? 10.ed. Rio de Janeiro: Paz e Terra, 1988. (O mundo hoje, 24).

HIGHWATER, J. Mito e sexualidade. Tradução de João Alves dos Santos. 1.ed. São Paulo: Saraiva, 1992.

MELO, S. M. M. Corpos no espelho: a percepção da corporeidade em professoras. 1.ed. Campinas: Mercado das Letras, 2004.

.; POCOVI, R. Educação e sexualidade. 2.ed. Florianópolis: UDESC, 2002. (Caderno Pedagógico, 1).

MORAES, J.; SCHMIDT, S. A mídia ensina "coisas de menino e de menina: um estudo sobre consumo, gênero e cultura infantil. In: XI CONGRESSO DE CIÊNCIA DA COMUNICAÇÃO NA REGIÃo SUL, 2010, Novo Hamburgo. Anais... Novo Hamburgo: INTERCOM, 2010. Disponível em: <http://www.intercom.org.br/papers/regionais/sul2010/resumos/R20-0891-1.pdf> Acesso em: 25 ago. 2011.

NUNES, C. A. Desvendando a sexualidade. 5.ed. Campinas: Papirus, 2005.

Filosofia, sexualidade e educação: as relações entre os pressupostos éticosociais e histórico-culturais presentes nas abordagens institucionais sobre a educação sexual escolar. 1996. 319f. Tese (Doutorado em Educação) - Faculdade de Educação, Universidade Estadual de Campinas, Campinas, 1996.

.; SILVA, E. A educação sexual da criança: subsídios teóricos e propostas práticas para uma abordagem da sexualidade para além da transversalidade. 2.ed. Campinas: Autores Associados, 2000. (Polêmicas do nosso tempo, 72).

SILVA, E. A. Filosofia, educação e educação sexual: matrizes filosóficas e determinações pedagógicas do pensamento de Freud, Reich e Foucault para a abordagem educacional da sexualidade humana. 2001. 300f. Tese (Doutorado em Educação) - Faculdade de Educação, Universidade Estadual de Campinas, Campinas, 2001.

SANTAELLA, L. Comunicação ubíqua: repercussões na cultura e na educação. São Paulo: Paulus, 2013. 